
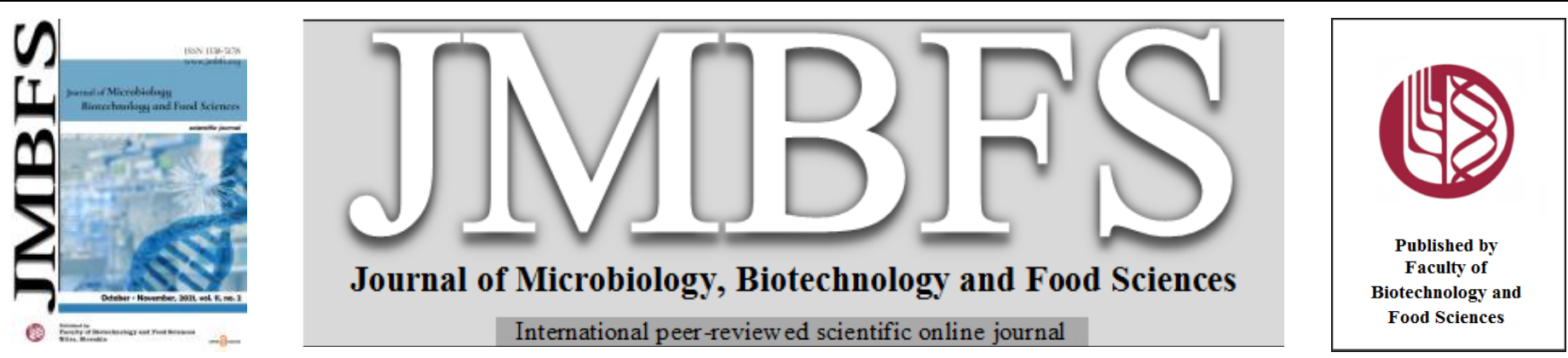

\title{
VIRULENCE FACTORS, ANTIBIOTIC RESISTANCE, AND ANTIMICROBIAL ACTIVITY OF ENTEROCOCCUS SPP. ISOLATED FROM DIFFERENT SOURCES IN ALGERIA
}

\author{
Abderrahmane Houicher ${ }^{*}$, Zuhal Alkay ${ }^{2}$, Mahdi Bourahla ${ }^{1}$ and Enes Dertli ${ }^{2}$ \\ Address(es): Prof. Abderrahmane Houicher, \\ ${ }^{1}$ Department of Agricultural Sciences, Faculty of Science, Amar Telidji University, BP 37 G, Laghouat 03000, Algeria. \\ ${ }^{2}$ Department of Food Engineering, Faculty of Engineering, Bayburt University, Bayburt 69000, Turkey.
}

*Corresponding author: a.houicher@lagh-univ.dz

https://doi.org/10.15414/jmbfs.1907

ARTICLE INFO

Received 5. 7. 2019

Revised 15. 4. 2021

Accepted 16. 4. 2021

Published 1. 10. 2021

Regular article

OPEN $\partial_{\text {ACCESS }}$

\section{ABSTRACT}

This study aimed to isolate and identify different Enterococcus spp. from diverse sources including dromedary raw milk, rhizospheric soil and natural saline water samples and to determine their antimicrobial activities and safety aspects. From these sources, distinct strains of E. faecium, E. durans, E. hirae, and E. gallinarum species were detected. No virulence factors were observed for six Enterococcus strains while none of the tested Enterococci harboured the genes encoding cytolysin and aggregation substance. All tested strains showed a high sensitivity to many antibiotics, particularly vancomycin, and exhibited a remarkable antagonist activity toward Salmonella typhimurium, Fusarium graminearum and Penicillium expansum. PCR testing of enterocins revealed the co-presence of ent $\mathrm{A}$ and ent $\mathrm{B}$ among all tested Enterococci. No hemolytic reaction was also detected in Enterococci isolates, except for six strains. Based on these findings, potential candidates for use as biocontrol agents or probiotic starters were selected for further studies.

Keywords: Enterococci, virulence factors, antibiotic resistance, antimicrobial activity, enterocin

\section{INTRODUCTION}

Enterococci are commensal inhabitants of the animal gastrointestinal tracts that commonly isolated from different environmental habitats such as animal and human feces, soil, plants, and water (Byappanahalli et al., 2012). Enterococcus species often occur in various food sources, in particular those of animal origin, such as dairy products. Recently, they are of increasing interest due to their potential techno-functional roles such as their roles in the preparation of different types of cheeses and the development of their sensory characteristics (Hanchi $\boldsymbol{e}$ al., 2018; Schirru et al., 2012). In Algeria, raw dromedary milk is an important part of the human diet traditionally consumed by nomadic peoples for its nutritional value and medicinal properties (Hassaïne et al., 2007; Merzouk et al., 2013). These potential positive roles are due to the presence of different strains of lactic acids bacteria (LAB) including Enterococcus species in dromedary milk yet little information is available on the LAB microflora of dromedary milk.

Enterococci are also frequently found in different environmental sources due to their heat resistance and their ability to survive adverse environmental conditions (Giard et al., 2001; Giraffa, 2002). Many bacteria have been found in rhizospheres associated with both plants and soil, and these bacteria have coevolved with phytopathogenic bacteria and fungi (Fhoula et al., 2013; Garbeva et al., 2004). Nevertheless, reports on Enterococci isolation from rhizospheric soil and their safety aspects remain scarce. In addition, Enterococcus species can be isolated from different aquatic environments and coastal marine habitats (Erdem et al., 2007; Ferguson et al., 2005; Moore et al., 2008), due to their capacity to tolerate high salt concentrations. However, little information is available on the isolation of Enterococcus species from saline water in different natural caves of salt mountains in which salt levels are generally higher than in sea and rivers.

In fact, Enterococci are widely distributed in different environmental habitats and their diversity depends on several environmental factors such as the geographica area and potential sources (Byappanahalli et al., 2012; Moore et al., 2008). To the best of our knowledge, the present study is the first research in Algeria that aims to provide new relevant information about the characterization of Enterococcus species isolated from dromedary raw milk, rhizospheric soil and natural saline water samples then to evaluate their antimicrobial activities and safety aspects in order to select potential candidates to be used as biocontrol agents or probiotic starters.

\section{MATERIAL AND METHODS}

\section{Sampling, isolation and genotypic characterization of Enterococci}

In this study, three different sources were used for the isolation of enterococci. Briefly, samples of dromedary raw milk were obtained from four different farms in the Laghouat region of Algeria. Samples were aseptically collected in sterile flasks after elimination of the first jets of milk, transferred to the laboratory in a cool box and kept under refrigeration at $4{ }^{\circ} \mathrm{C}$ until analysis. Enterococci were isolated by spreading $0.1 \mathrm{~mL}$ of the selected dilutions of samples on Enterococcus Selective Agar (ESA) (SIGMA ALDRICH Co., St. Louis, MO USA) and typical maroon or dark red colonies were isolated after 48 hours of incubation at $37{ }^{\circ} \mathrm{C}$. Regarding the other samples, rhizospheric soil was obtained from five different agricultural enterprises in the Jijel region of Algeria. Soil samples were taken from the rhizosphere area of olive plants with sterile spoons $(15-20 \mathrm{~cm}$ depth) and saved into sterile nylon bags. For the natural saline water, samples were obtained from three different natural caves of a salt mountain located in Tadjrouna, Laghouat region of Algeria. Saline water samples were collected in sterile flasks from natural sources and kept in a cool box during the transportation to the laboratory. The enrichment method was then used for enterococci isolation from both rhizospheric soil and saline water samples following the procedure described by Zamudio-Maya $\boldsymbol{e t}$ al. (2008) with some modifications. The samples were inoculated into Brain Heart Infusion (BHI) broth and incubated at $37{ }^{\circ} \mathrm{C}$ for 48 hours. Then, $0.1 \mathrm{~mL}$ from diluted cultures was spread onto ESA plates and typical colonies were isolated after incubation The purity of all isolates from milk, soil, and water samples was checked by further spreading on ESA, followed by microscopic examination, Gram staining, catalase and growth tests: esculin hydrolysis, growth at $\mathrm{pH} 9.6$ and in the presence of $6.5 \% \mathrm{NaCl}$, as well as growth at $10{ }^{\circ} \mathrm{C}$ and $45{ }^{\circ} \mathrm{C}$. Phenotypic identification was also carried out using the miniaturized API 20 Strep tests (BIOMÉRIEUX, Marcy l'Etoile, France).

RAPD-PCR analysis was used for the genotypic discrimination of all isolates and conducted with primer M13 as described elsewhere (Dertli et al., 2016). The $\sim 1.5 \mathrm{~kb} 16 \mathrm{~S}$ rRNA gene of each selected strain was amplified with primers AMP F and AMP R, as described by Baker et al. (2003), and PCR analysis was performed under the conditions described previously by Dertli et al. (2016) Sequence analysis results were examined with the NCBI database using the BLAST program. The phylogenetic tree was created using neighbour-joining bootstrap method (1000 replicates) and MEGA7 was used for all phylogenetic 
analyses, as described by Tamura et al. (2011). The 16S rRNA sequences of the isolates were submitted to the Genbank under the accession numbers of MT880256-MT880272.

\section{Screening of Enterococci for virulence determinants and hemolytic activity}

The screening of Enterococci for different virulence determinants was carried out by PCR using specific conditions and primers (Eaton and Gasson, 2001). Eight virulence factors were investigated: $c o b$, agg, efaAfs, efaAfm, cylA, cylB, esp, and gelE. As described above, genomic DNA was isolated from Enterococci strains and used as the DNA template in PCR reactions. PCR and the melting temperature of each primer set were performed according to Eaton and Gasson (2001).

For the detection of hemolysin production, overnight cultures of Enterococcus strains were spread onto Blood Agar Base (MERCK, Kenilworth, NJ, USA) plates supplemented with $5 \%(\mathrm{v} / \mathrm{v})$ of sheep blood as described by Yoon $\boldsymbol{e t}$ al. (2008). No hemolytic reaction around colonies, a partial hydrolysis or the presence of a clear zone of hydrolysis was interpreted as $\gamma$ hemolysis, $\alpha$ hemolysis and $\beta$ hemolysis, respectively, after incubation at $37^{\circ} \mathrm{C}$ for $24-48 \mathrm{~h}$.

\section{Antibiotic sensitivity assay}

The antibiotic resistance of the Enterococci strains was tested against nine antibiotics using the agar disc diffusion test. The following antibiotics were tested: streptomycin $(\mathrm{S}, 10 \mu \mathrm{g})$, tetracycline $(\mathrm{TE}, 30 \mu \mathrm{g})$, kanamycin $(\mathrm{K}, 30 \mu \mathrm{g})$, ampicillin (AMP, $10 \mu \mathrm{g})$, erythromycin (E, $15 \mu \mathrm{g})$, penicillin $(\mathrm{P}, 10 \mu \mathrm{g})$ chloramphenicol $(\mathrm{C}, 30 \mu \mathrm{g})$, oxytetracycline (OT, $30 \mu \mathrm{g})$, and vancomycin (VA, $30 \mu \mathrm{g}$ ) (OXOID, Basingstoke, UK). For each strain, 1\% inoculum from overnight culture was added to $\mathrm{BHI}$ agar at $45-50{ }^{\circ} \mathrm{C}$ and poured into plates to obtain a final concentration of $10^{6}-10^{7} \mathrm{CFU} / \mathrm{mL}$, and then antibiotic discs were dispensed onto the inoculated agar surface. Inhibition zone diameters around the discs were measured after overnight incubation at $37^{\circ} \mathrm{C}$ and expressed as millimeter $(\mathrm{mm})$ following the recommendations of NCCLS (2004)

\section{Detection of antimicrobial activity and enterocin coding genes}

To determine the antimicrobial activity of Enterococci against pathogenic bacteria and fungi, the agar well diffusion assay was used. Briefly, the supernatants of isolates were obtained from overnight cultures by centrifugation for $5 \mathrm{~min}$ at $14,000 \mathrm{rpm}$, followed by filtration through a sterile syringe filter $(0.22 \mu \mathrm{m})$. The filtered supernatants were treated with catalase (MERCK) for 30 min at $25{ }^{\circ} \mathrm{C}$ after adjusting the $\mathrm{pH}$ to 6.0 with $\mathrm{NaOH}$. In this study, four bacterial strains were evaluated: Escherichia coli BC 1402, Salmonella typhimurium RSSK 95091, Staphylococcus aureus BC 7231, and Yersinia enterocolitica ATCC 27729. The indicator strains were obtained from Pamukkale University, Food Engineering Department Culture Collection (PUFECC, WDCM 1019). Al pathogens were cultured aerobically in Tryptic Soy Broth (TSB) medium at 37 ${ }^{\circ} \mathrm{C}$ for $24 \mathrm{~h}$. Wells ( $5 \mathrm{~mm}$ diameter) were cut into TSB agar plates containing $10^{6}$ cells per $\mathrm{mL}$ of the target pathogen strains and then $50 \mu \mathrm{L}$ supernatants were added to the wells. After overnight incubation at $37^{\circ} \mathrm{C}$, the inhibition zones were scored and expressed as follows: ++ , strong inhibition with detectable clear zones around the wells; + , weak inhibition around the wells; - , no inhibition zone.

For the antifungal assay, 4 filamentous fungal strains were tested: Fusarium graminearum MUCL 53452, Aspergillus parasiticus CBS 100926, Aspergillus flavus NRRL 3251, and Penicillium expansum MUCL 29192. For each fungal strain, inoculum was obtained from 7-14 days cultures grown on Potato Dextrose Agar (PDA) at $25{ }^{\circ} \mathrm{C}$, and then $50 \mu \mathrm{L}$ supernatants were added to the wells cut into PDA plates containing $0.4-5 \times 10^{4}$ fungal spores per $\mathrm{mL}$. After aerobic incubation at $30^{\circ} \mathrm{C}$ for $48 \mathrm{~h}$, the inhibition zones around the wells were examined and graded as described above (Magnusson and Schnurer, 2001).

The PCR detection of the genes encoding enterocins (A and B) was performed using the conditions described by Fontana et al. (2015) with the specific enterocin PCR primers (Du Toit et al., 2000). Amplicon sizes of 126 and 162 bp were checked on agarose gels in order to confirm the presence of ent $\mathrm{A}$ and ent $\mathrm{B}$, respectively.

\section{RESULTS}

\section{Identification and genotypic characterization of isolates}

Among 100 strains randomly selected from different samples, 33 isolates were identified as presumptive Enterococci based on the criteria mentioned above. Further, the isolates were confirmed as members of Enterococcus based on phenotypic characterization using biochemical identification tests provided by the API 20 Strep System. Following these processes and genotypic discrimination, identification of the selected isolates revealed the presence of 8 Enterococcus faecium, 4 Enterococcus hirae, 3 Enterococcus durans, and 2 Enterococcus gallinarum strains from different sources among these isolates as can be seen in table 1 .
Phylogenetic tree in Figure 1 shows the relationship between Enterococci strains based on the MEGA7 alignments of the 16S rRNA genes using the neighborjoining method. The cluster alignments analysis of the Enterococci showed that E. faecium, E. hirae and E. durans were close but formed different subgroups and importantly E. faecium strains DM 19, KM 1 and KM 2 were separated from the other tested E. faecium strains suggesting potential differences in terms of ancestral genetics. Compared with the other strains, E. gallinarum strains also formed a different subgroup (Figure 1). Our results revealed the diversity of Enterococcus in different environments and these strains were further tested for both antimicrobial activity and safety properties.

Table 1 Selected Enterococcus strains for 16S rRNA gene sequencing and their natural sources

\begin{tabular}{lll}
\hline Codes & 16S rRNA Sequencing & Sources \\
\hline DM 29 & Enterococcus gallinarum & \\
DM 26 & Enterococcus gallinarum & \\
DM 20 & Enterococcus durans & \\
DM 19 & Enterococcus faecium & Dromedary raw milk \\
DM 4 & Enterococcus durans & \\
DM 34 & Enterococcus durans & \\
KM 8 & Enterococcus hirae & \\
KM 6 & Enterococcus hirae & Natural saline water \\
KM 2 & Enterococcus faecium & \\
KM 1 & Enterococcus faecium & \\
KM 14 & Enterococcus faecium & \\
KM 12 & Enterococcus hirae & Rhizospheric soil \\
KM 11 & Enterococcus hirae & \\
\hline RS 31 & Enterococcus faecium & \\
RS 29 & Enterococcus faecium & \\
RS 4 & Enterococcus faecium & \\
RS 25 & Enterococcus faecium &
\end{tabular}

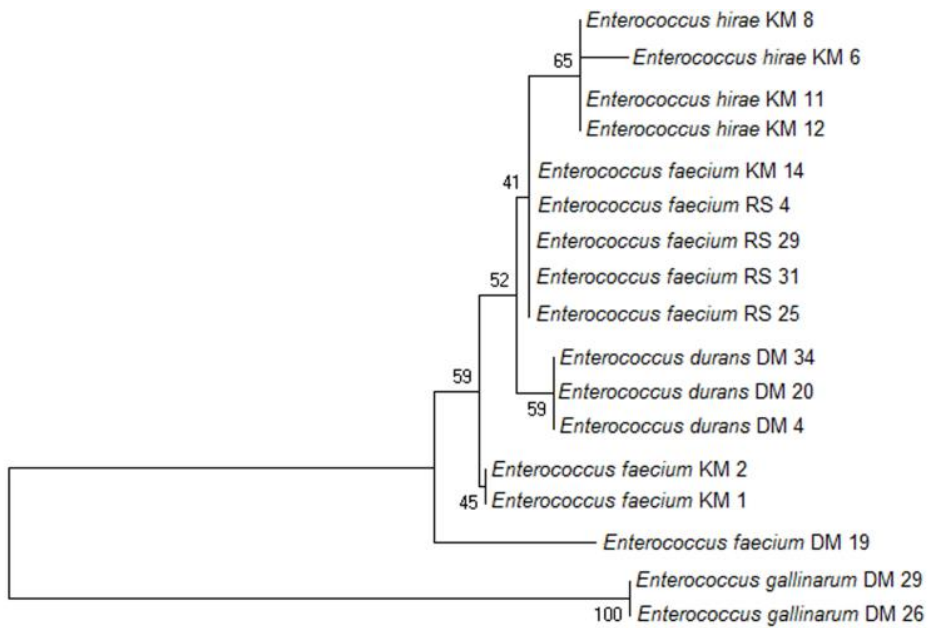

\subsection{0}

Figure 1 Phylogenetic tree based on the MEGA7 alignments of the 16S rRNA genes showing the relationship between Enterococci strains

\section{Virulence determinants and hemolysin production}

Screening of the presence of Enterococcus virulence factors is considered as one of the main concerns about their safety for use as biocontrol agents or probiotic starters. As shown in table 2, six strains were negative for the tested virulent factors. However, E. faecium DM 19 harboured multiple virulence determinants in which five virulence genes encoding $c o b$, efaAfs, efaAfm, esp, and gelE were presented. Two virulence genes encoding efaAfm and cob were also detected in the strain E. faecium RS 29, whereas the other tested strains possessed only one virulence factor $(\mathrm{efaAfm})$. In general, all tested Enterococci strains were negative for the tested genes encoding cytolysin ( $c y l A$ and $c y l B)$ and aggregation substance $(\mathrm{agg})$ which is a good characteristic for their potential biotechnological applications.

Another important role in enterococcal virulence is the hemolysin production by enterococci which is considered as a health risk factor. A partial hydrolysis ( $\alpha$ 
hemolysis) of sheep blood was observed for six E. faecium while no hemolytic

reaction ( $\gamma$ hemolysis) was detected in the other tested strains (Tab 2).

Table 2 Occurrence of virulence traits and hemolytic activity among tested Enterococcus strains

\begin{tabular}{|c|c|c|c|c|c|c|c|c|c|c|}
\hline Strains & $A g g$ & $c o b$ & cylA & $c y l B$ & efaAfs & efaAfm & esp & gelE & $\begin{array}{c}\alpha \\
\text { hemolyse } \\
\end{array}$ & $\gamma$ hemolyse \\
\hline Enterococcus gallinarum DM 29 & - & - & - & - & - & - & - & - & - & + \\
\hline Enterococcus gallinarum DM 26 & - & - & - & - & - & - & - & - & - & + \\
\hline Enterococcus durans DM 20 & - & - & - & - & - & + & - & - & - & + \\
\hline Enterococcus faecium DM 19 & - & + & - & - & + & + & + & + & + & - \\
\hline Enterococcus durans DM 4 & - & - & - & - & - & + & - & - & - & + \\
\hline Enterococcus durans DM 34 & - & - & - & - & - & + & - & - & - & + \\
\hline Enterococcus hirae KM 8 & - & - & - & - & - & - & - & - & - & + \\
\hline Enterococcus hirae KM 6 & - & - & - & - & - & - & - & - & - & + \\
\hline Enterococcus faecium $\mathrm{KM} 2$ & - & - & - & - & - & + & - & - & - & + \\
\hline Enterococcus faecium KM 1 & - & - & - & - & - & + & - & - & - & + \\
\hline Enterococcus faecium KM 14 & - & - & - & - & - & + & - & - & + & - \\
\hline Enterococcus hirae KM 12 & - & - & - & - & - & - & - & - & - & + \\
\hline Enterococcus hirae KM 11 & - & - & - & - & - & - & - & - & - & + \\
\hline Enterococcus faecium RS 31 & - & - & - & - & - & + & - & - & + & - \\
\hline Enterococcus faecium RS 29 & - & + & - & - & - & + & - & - & + & - \\
\hline Enterococcus faecium RS 4 & - & - & - & - & - & + & - & - & + & - \\
\hline Enterococcus faecium $\mathrm{RS} 25$ & - & - & - & - & - & + & - & - & + & - \\
\hline
\end{tabular}

-: not detected, +: detected

\section{Antibiotic resistance}

The results of antibiotic resistance of Enterococci strains are reported in table 3. With the exceptions of E. faecium RS 29 and RS 31, our isolates were resistant to streptomycin and kanamycin, but sensitive to other tested antibiotics. By contrast, both E. faecium RS 29 and RS 31 were found to be resistant to ampicillin and penicillin, but susceptible to other antibiotics (Tab 3). In general, no vancomycin resistance was recorded among tested Enterococci strains, while seven isolates were intermediate-resistant to erythromycin.

Table 3 Antibiotic sensitivity profiles of Enterococcus isolates

\begin{tabular}{|c|c|c|c|c|c|c|c|c|c|}
\hline Strains & $\mathrm{S}^{*}$ & $\mathrm{~K}$ & $\mathrm{TE}$ & AMP & $\mathrm{E}$ & $\mathrm{C}$ & $\mathrm{P}$ & OT & VA \\
\hline Enterococcus gallinarum DM 29 & $\mathrm{R}$ & $\mathrm{R}$ & $\mathrm{S}$ & $\mathrm{S}$ & $\mathrm{S}$ & $\mathrm{S}$ & $\mathrm{S}$ & $\mathrm{S}$ & $\mathrm{S}$ \\
\hline Enterococcus gallinarum DM 26 & $\mathrm{R}$ & $\mathrm{R}$ & $\mathrm{S}$ & $\mathrm{S}$ & $\mathrm{S}$ & $\mathrm{S}$ & $\mathrm{S}$ & $\mathrm{S}$ & $\mathrm{S}$ \\
\hline Enterococcus durans DM 20 & $\mathrm{R}$ & $\mathrm{R}$ & $\mathrm{S}$ & $\mathrm{S}$ & I & $\mathrm{S}$ & $\mathrm{S}$ & $\mathrm{S}$ & $\mathrm{S}$ \\
\hline Enterococcus faecium DM 19 & $\mathrm{R}$ & $\mathrm{R}$ & $\mathrm{S}$ & $\mathrm{S}$ & $\mathrm{S}$ & $\mathrm{S}$ & $\mathrm{S}$ & $\mathrm{S}$ & $\mathrm{S}$ \\
\hline Enterococcus durans DM 4 & $\mathrm{R}$ & $\mathrm{R}$ & $\mathrm{S}$ & $\mathrm{S}$ & I & S & $\mathrm{S}$ & $\mathrm{S}$ & $\mathrm{S}$ \\
\hline Enterococcus durans DM 34 & $\mathrm{R}$ & $\mathrm{R}$ & $\mathrm{S}$ & $\mathrm{S}$ & $\mathrm{S}$ & $\mathrm{S}$ & $\mathrm{S}$ & $\mathrm{S}$ & $\mathrm{S}$ \\
\hline Enterococcus hirae KM 8 & $\mathrm{R}$ & $\mathrm{R}$ & $\mathrm{S}$ & $\mathrm{S}$ & $\mathrm{S}$ & $\mathrm{S}$ & $\mathrm{S}$ & $\mathrm{S}$ & $\mathrm{S}$ \\
\hline Enterococcus hirae KM 6 & $\mathrm{R}$ & $\mathrm{R}$ & $\mathrm{S}$ & $\mathrm{S}$ & $\mathrm{S}$ & $\mathrm{S}$ & $\mathrm{S}$ & $\mathrm{S}$ & $\mathrm{S}$ \\
\hline Enterococcus faecium $\mathrm{KM} 2$ & $\mathrm{R}$ & $\mathrm{R}$ & $\mathrm{S}$ & $\mathrm{S}$ & I & $\mathrm{S}$ & $\mathrm{S}$ & $\mathrm{S}$ & $\mathrm{S}$ \\
\hline Enterococcus faecium KM 1 & $\mathrm{R}$ & $\mathrm{R}$ & $\mathrm{S}$ & $\mathrm{S}$ & I & $\mathrm{S}$ & $\mathrm{S}$ & $\mathrm{S}$ & $\mathrm{S}$ \\
\hline Enterococcus faecium KM 14 & $\mathrm{R}$ & $\mathrm{R}$ & $\mathrm{S}$ & $\mathrm{S}$ & I & $\mathrm{S}$ & $\mathrm{S}$ & $\mathrm{S}$ & $\mathrm{S}$ \\
\hline Enterococcus hirae KM 12 & $\mathrm{R}$ & $\mathrm{R}$ & $\mathrm{S}$ & $\mathrm{S}$ & $\mathrm{S}$ & S & $\mathrm{S}$ & $\mathrm{S}$ & $\mathrm{S}$ \\
\hline Enterococcus hirae KM 11 & $\mathrm{R}$ & $\mathrm{R}$ & $\mathrm{S}$ & $\mathrm{S}$ & $\mathrm{S}$ & $\mathrm{S}$ & $\mathrm{S}$ & $\mathrm{S}$ & $\mathrm{S}$ \\
\hline Enterococcus faecium RS 31 & $\mathrm{~S}$ & $\mathrm{~S}$ & $\mathrm{~S}$ & $\mathrm{R}$ & $\mathrm{S}$ & $\mathrm{S}$ & $\mathrm{R}$ & $\mathrm{S}$ & $\mathrm{S}$ \\
\hline Enterococcus faecium RS 29 & $\mathrm{~S}$ & $\mathrm{~S}$ & $\mathrm{~S}$ & $\mathrm{R}$ & $\mathrm{S}$ & $\mathrm{S}$ & $\mathrm{R}$ & $\mathrm{S}$ & $\mathrm{S}$ \\
\hline Enterococcus faecium $\mathrm{RS} 4$ & $\mathrm{R}$ & $\mathrm{R}$ & $\mathrm{S}$ & $\mathrm{S}$ & $\mathrm{I}$ & $\mathrm{S}$ & $\mathrm{S}$ & $\mathrm{S}$ & $\mathrm{S}$ \\
\hline Enterococcus faecium RS 25 & $\mathrm{R}$ & $\mathrm{R}$ & $\mathrm{S}$ & $\mathrm{S}$ & I & $\mathrm{S}$ & $\mathrm{S}$ & $\mathrm{S}$ & $\mathrm{S}$ \\
\hline Resistant (R) & $<13^{* *}$ & $\leq 13$ & $\leq 14$ & $\leq 16$ & $\leq 13$ & $\leq 17$ & $\leq 14$ & $\leq 14$ & $\leq 14$ \\
\hline Intermediate-resistant (I) & - & $14-17$ & $15-18$ & - & $14-22$ & $18-20$ & - & $15-18$ & $15-16$ \\
\hline Sensitive $(\mathrm{S})$ & $\geq 15$ & $\geq 18$ & $\geq 19$ & $\geq 17$ & $\geq 23$ & $\geq 21$ & $\geq 15$ & $\geq 19$ & $\geq 17$ \\
\hline
\end{tabular}
Inhibition zone diameters expressed as millimeter $(\mathrm{mm})$

\section{Determination of antimicrobial activity and enterocin coding genes}

Table 4 summarizes the antimicrobial activity of Enterococci strains toward pathogenic bacteria and fungi. E. faecium RS 29 and RS 31 were the only two strains which showed no inhibition against the tested pathogenic bacteria. With the exception of E. faecium RS 4, no activity was observed against E. coli. Additionally, only two strains, E. durans DM 34 and E. faecium RS 4 indicated moderate inhibitory activities against $Y$. enterolitica. However, the tested Enterococci strains exhibited considerable levels of inhibitory activity against $S$ typhimurium. Apart from 6 strains, the isolates also showed antagonistic effects toward S. aureus (Tab 4). For the antifungal activity, all Enterococci strains exerted strong inhibitory effects toward $F$. graminearum and $P$. expansum. The isolates also displayed inhibition of the growth at a lower extent against $A$. parasiticus, except for five strains. Similarly, 8 out of 17 Enterococci strains did not show any antifungal activity against A. flavus (Tab 4).

In this study, the characterized strains (17 isolates) were also subjected to PCR detection of the genes encoding enterocins (ent $\mathrm{A}$ and ent $\mathrm{B}$ ) using specific primers. The results revealed that all isolates harboured both entA and entB genes within their genome (data not shown). 
Table 4 Antimicrobial activity of Enterococci strains toward selected pathogenic bacteria and fungi

\begin{tabular}{|c|c|c|c|c|c|c|c|c|}
\hline Strains & $\begin{array}{c}S . \\
\text { typhimurium } \\
\text { RSSK } \\
95091 \\
\end{array}$ & $\begin{array}{c}E \text {-coli } \\
\text { BC } 1402\end{array}$ & $\begin{array}{l}\text { S. aureus } \\
\text { BC } 7231\end{array}$ & $\begin{array}{l}\text { Y. enterolitica } \\
\text { ATCC } 27729\end{array}$ & $\begin{array}{l}F . \text { graminearum } \\
\text { MUCL } 53452\end{array}$ & $\begin{array}{l}\text { A. parasiticus } \\
\text { CBS } 100926\end{array}$ & $\begin{array}{c}\text { A. flavus } \\
\text { NRRL } 3251\end{array}$ & $\begin{array}{l}\text { P. expansum } \\
\text { MUCL } 29192\end{array}$ \\
\hline Enterococcus gallinarum DM 29 & ++ & - & + & - & + & + & + & ++ \\
\hline Enterococcus gallinarum DM 26 & ++ & - & ++ & - & ++ & - & + & ++ \\
\hline Enterococcus durans DM 20 & + & - & + & - & ++ & + & - & ++ \\
\hline Enterococcus faecium DM 19 & + & - & ++ & - & ++ & - & + & ++ \\
\hline Enterococcus durans DM 4 & + & - & - & - & ++ & - & + & ++ \\
\hline Enterococcus durans DM 34 & + & - & + & + & ++ & + & - & ++ \\
\hline Enterococcus hirae KM 8 & + & - & + & - & + & + & - & ++ \\
\hline Enterococcus hirae KM 6 & ++ & - & + & - & + & + & + & ++ \\
\hline Enterococcus faecium KM 2 & + & - & + & - & ++ & + & + & ++ \\
\hline Enterococcus faecium KM 1 & + & - & - & - & ++ & + & + & ++ \\
\hline Enterococcus faecium KM 14 & + & - & - & - & ++ & + & - & + \\
\hline Enterococcus hirae KM 12 & ++ & - & + & - & ++ & + & + & ++ \\
\hline Enterococcus hirae KM 11 & + & - & + & - & + & + & + & + \\
\hline Enterococcus faecium RS 31 & - & - & - & - & + & + & - & ++ \\
\hline Enterococcus faecium RS 29 & - & - & - & - & ++ & - & - & ++ \\
\hline Enterococcus faecium RS 4 & + & + & - & + & ++ & + & - & ++ \\
\hline Enterococcus faecium RS 25 & ++ & - & ++ & - & ++ & - & - & ++ \\
\hline
\end{tabular}

++ : Strong inhibition with detectable clear zones around the wells, +: weak inhibition around the wells, $-:$ no inhibition zone

\section{DISCUSSION}

Enterococcus species are found in various sources of raw foods of animal origin, such as raw milk from goat, ewe and cow (Yerlikaya and Akbulut, 2020; Hanchi et al., 2018; Foulquié Moreno et al., 2006). In the present work, six Enterococci strains were isolated from dromedary raw milk and identified as $E$. durans (3 isolates), E. gallinarum (2 isolates), and E. faecium (1 isolate), which clustered in different subgroups. Only few reports have shown the predominance of Enterococci in dromedary raw milk and suggested that they are good candidates for potential dairy applications such as fermented camel milk products (Hassaïne et al., 2007; Hassaïne et al., 2008; Khay et al., 2011). Enterococci are also found frequently in soils, water, and plants as a result mainly of fecal contamination (Giraffa, 2002), but other studies have suggested that these bacteria were possibly derived from nonfecal sources (Klibi et al., 2012). Our results showed the predominance of $E$. faecium species in rhizospheric soil samples while saline water samples revealed the presence of $E$. hirae and $E$. faecium species. Similarly, Klibi et al. (2012) reported the prevalence of $E$. faecium species (97\%) isolated from olive rhizospheres in Tunisia. In addition, Enterococcus species such as E. durans, E. hirae, and E. gallinarum were commonly found in variety of habitats especially soil, water, and vegetables (Abriouel et al., 2008). E. faecium, E. faecalis, E. hirae, E. casseliflavus and E. mundtii are also the predominant species isolated from intertidal and marine sediments and ocean water (Ferguson et al., 2005; Moore et al., 2008). This predominance of Enterococci could be related to their broad spectrum of natural tolerance to adverse environmental conditions and high salt concentrations (Giraffa, 2002; Hardwood et al., 2000).

Several studies have extensively focused on the incidence of virulence determinants in Enterococci species reporting that a remarkable low occurrence of virulence genetic determinants was detected in Enterococcus isolates from foods or used as starters (Eaton and Gasson, 2001), but also in those from water and soil (Abriouel et al., 2008). In the present study, six Enterococcus strains isolated from dromedary raw milk and natural saline water samples were free of the tested virulence factors while none of our Enterococci isolates harboured cytolysin ( $c y l A$ and $c y l B)$ and aggregation substance $(a g g)$ genes. Eaton and Gasson (2001) reported that all tested E. faecium and E. durans strains were clear of the cytolysin and aggregation substance genes compared with E. faecalis isolates. In agreement with our findings, previous reports also concluded that Enterococci strains not carrying virulence factors, especially cytolysin genes, may be considered as a good characteristic for their food applications (Ahmadova et al., 2013; De Vuyst et al., 2003). However, five virulence genes encoding efaAfs, efaAfm, esp, cob, and gelE were harboured in E. faecium DM 19 while the other tested strains carried one to two virulence genes. It is noteworthy that efaAfm was highly detected among our isolates, especially rhizospheric Enterococci. Similarly, high incidence of virulence determinants efaA (efaAfs and/or efaAfm) among food and water isolates of Enterococcus was previously recorded by Eaton and Gasson (2001) and Abriouel et al. (2008), nevertheless, very little information on the incidence of virulence factors among rhizospheric Enterococci has been published (Klibi et al., 2012). In addition, a much lower presence of $e s p, c o b$, and gelE genes or even absence in Enterococci isolates from dromedary raw milk, saline water and rhizospheric soil samples is in accordance with the previous reports concerning food, water and soil isolates (Abriouel et al., 2008; Eaton and Gasson, 2001; Klibi et al., 2012).

The present findings also indicate that none of the tested Enterococcus strains showed $\beta$ hemolysis. However, a partial hydrolysis ( $\alpha$ hemolysis) was observed for six E. faecium strains while no hemolytic reaction ( $\gamma$ hemolysis) was detected in the other tested strains. The absence of hemolytic activity within Enterococci species should be regarded as a significant selection criterion for their safe use taking into account vancomycin sensitivity and absence of cytolysin gene (De Vuyst et al., 2003).

The frequent Enterococci resistance to commonly used antibiotics and the risk of transmitting antibiotic resistant genes to other opportunistic or pathogenic bacteria are particular concerns for their safe use in foods or as biocontrol agents (Giraffa, 2002). In the present study, antibiotic susceptibility results showed that our isolates were resistant to streptomycin and kanamycin, except for two strains. Resistance to cephalosporins and aminoglycosides among certain Enterococci species has been reviewed by Morrison et al. (1997) and Tendolkar $\boldsymbol{e t}$ al. (2003). Moreover, several authors have reported on the resistance of Enterococci to kanamycin and streptomycin (Ahmadova et al., 2013; Hosseini et al., 2009; Mathur and Singh, 2005). In this study, only two E. faecium stains isolated from rhizospheric soil samples were found to be resistant to ampicillin and penicillin. A similar observation was reported by Abriouel et al. (2008) on the resistance to ampicillin and penicillin within Enterococcus species especially $E$. faecium and E. faecalis isolates from soil and water. Nevertheless, few studies have also reported on the antibiotic resistance of Enterococcus from rhizospheric soil (Klibi et al., 2012; Fhoula et al., 2013). Generally, our results showed a high sensitivity of all isolates to the tested antibiotics, especially vancomycin which is considered as a major health concern worldwide.

Enterococci produce powerful enterocins which are of great interest because of their large spectra of activity against pathogenic bacteria and fungi. In this study, only two isolates did not inhibit the tested pathogenic bacteria while the others exhibited varying levels of antibacterial activity. In addition, some isolates showed considerable inhibitory effects against $S$. typhimurium and $S$. aureus. Several authors concluded that any activity of enterocins against Gram-negative bacteria is very rare due to the lipopolysaccharide layer in their outer membranes (Ahmadova et al., 2013; Schirru et al., 2012; Belgacem et al., 2010; Gong et al., 2010). However, our isolates exhibited remarkable antagonist activity toward S. typhimurium which could be of great interest. Previous reports also proved that bacteriocin-producing Enterococci displayed a strong inhibitory effect against a broad range of Gram-positive bacteria including Staphylococcus and Listeria (Yerlikaya and Akbulut, 2020; Fhoula et al., 2013; Rivas et al., 2012; Schirru et al., 2012), which are in agreement with our findings. Moreover, all the tested Enterococci strains exerted strong inhibitory effects toward F. graminearum and $P$. expansum. Similar to our results, E. faecium PC4.1 exhibited strong inhibition growth at the same extent for Fusarium ssp. and Cladosporium (Hadji-Sfaxi et al., 2011), while Fhoula et al. (2013) confirmed the antifungal efficacy of Enterococcus strains against most of the tested postharvest fungi (A. niger, $P$. expansum, and $B$. cinerea) and highlighted their potential use as biocontrol agents. Many Enterococcus species produce a large number and diverse classes of useful antimicrobial peptides or enterocins (Foulquié Moreno et al., 2006). Our results revealed the co-presence of ent $\mathrm{A}$ and ent $\mathrm{B}$ among all the isolates which has already been reported by other studies (Özden Tuncer et al., 2013; Rivas et al., 2012). Vendera et al. (2019) and De Vuyst et al. (2003) also demonstrated the synergistic effects of enterocin A and enterocin B, and the combined use of both enterocins could be more better in exhibiting a large spectrum of activity against a wide range of pathogenic microorganisms.

\section{CONCLUSIONS}

In conclusion, the obtained results showed the diversity of Enterococcus strain isolated from different sources in Algeria which may depend on different geographic regions and environmental habitats from which they were isolated. Among the tested Enterococcus isolates, six strains (E. gallinarum DM 29, E. 
gallinarum DM 26, E. hirae KM 6, E. hirae KM 8, E. hirae KM 11, and E. hirae KM 12) were selected for further investigations based on their safety aspects. These included the lack of tested virulence factors and hemolytic activity, the high sensitivity to vancomycin and the exhibition of remarkable antagonist effect against tested pathogenic bacteria and fungi. This indicated their potential as candidates for biocontrol agents or probiotic starters. However, more research is needed to study the chemical characterization of the molecular structure of active compounds produced by these strains.

\section{REFERENCES}

Abriouel, H., Ben Omar, N., Cobo Molinos, A., López, R., Grande, M. J. Martínez-Viedma, P., Ortega, P., Martínez Cañamero, M., \& Galvez, A. (2008) Comparative analysis of genetic diversity and incidence of virulence factors and antibiotic resistance among enterococcal populations from raw fruit and vegetable foods, water and soil, and clinical samples. International Journal of Food Microbiology, 123(1-2),

$38-49$.

https://doi.org/10.1016/j.ijfoodmicro.2007.11.067

Ahmadova, A., Todorov, S. D., Choiset, Y., Rabesona, H., Mirhadi Zadi, T. M., Kuliyev, A., Franco, B. D. G. d. M., Chobert, J. M., \& Haertlé, T. (2013) Evaluation of antimicrobial activity, probiotic properties and safety of wild strain Enterococcus faecium AQ71 isolated from Azerbaijani Motal cheese. Food Control, 30(2), 631-641. https://doi.org/10.1016/j.foodcont.2012.08.009

Baker, G. C., Smith, J. J., \& Cowan, D. A. (2003). Review and re-analysis of domain-specific 16S primers. Journal of Microbiological Methods, 55(3), 541555. https://doi.org/10.1016/j.mimet.2003.08.009

Belgacem, Z. B., Abriouel, H., Ben Omar, N., Lucas, R., Martinez-Canamero, M., Galvez, A., \& Manai, M. (2010). Antimicrobial activity, safety aspects, and some technological properties of bacteriocinogenic Enterococcus faecium from artisanal Tunisian fermented meat. Food Control, 21(4), 462-470. https://doi.org/10.1016/j.foodcont.2009.07.007

Byappanahalli, M. N., Nevers, M. B., Korajkic, A., Staley, Z. R., \& Harwood, V.J. (2012). Enterococci in the Environment. Microbiology and Molecular Biology Reviews, 76(4), 685-706. https://doi.org/10.1128/MMBR.00023-12

Dertli, E., Mercan, E., Arıcı, M., Yılmaz, M. T., \& Sagdıç, O. (2016) Characterisation of lactic acid bacteria from Turkish sourdough and determination of their exopolysaccharide (EPS) production characteristics. $L W T$ Food Science and Technology, 71, 116-124. https://doi.org/10.1016/j.lwt.2016.03.030

De Vuyst, L., Foulquié Moreno, M. R., \& Revets, H. (2003). Screening for enterocines and detection of hemolysin and vancomycin resistance in enterococci of different origins. International Journal of Food Microbiology, 84(3), 299-318. https://doi.org/10.1016/S0168-1605(02)00425-7

Du Toit, M., Franz, C. M. A. P., Dicks, L. M. T., \& Holzapfel, W.H. (2000) Preliminary characterization of bacteriocins produced by Enterococcus faecium and Enterococcus faecalis isolated from pig faeces. Journal of Applied Microbiology, 88(3), 482-494. $\quad$ http://dx.doi.org/10.1046/j.13652672.2000.00986.x

Eaton, T. J., \& Gasson, M. J. (2001). Molecular screening of Enterococcus virulence determinants and potential for genetic exchange between food and medical isolates. Applied and Environmental Microbiology, 67(4), 1628-1635. https://doi.org/10.1128/AEM.67.4.1628-1635.2001

Erdem, A. K., Arslan, E. O., Yurudu, N. O. S., Zeybek, Z., Dogruoz, N., \& Cotuk, A. (2007). Isolation and identification of enterococci from seawater samples: assessment of their resistance to antibiotics and heavy metals. Environmental Monitoring Assessment, 125(1-3), 219-228. https://doi.org/10.1007/s10661-006-9506-0

Ferguson, D. M., Moore, D. F., Getrich, M. A., \& Zhowandai, M. H. (2005) Enumeration and speciation of enterococci found in marine and intertidal sediments and coastal water in southern California. Journal of Applied Microbiology, 99(3), 598-608. https://doi.org/10.1111/j.1365-2672.2005.02660.x Fhoula, I., Najjari, A., Turki, Y., Jaballah, S., Boudabous, A., \& Ouzari, H (2013). Diversity and antimicrobial properties of lactic acid bacteria isolated from rhizosphere of olive trees and desert truffles of Tunisia. BioMed Research International. $\mathrm{http} / / / \mathrm{dx}$.doi.org/10.1155/2013/405708

Fontana, C., Cocconcelli, P. S., Vignolo, G., \& Saavedra, L. (2015). Occurrence of antilisterial structural bacteriocins genes in meat borne lactic acid bacteria. Food Control, 47, 53-59. https://doi.org/10.1016/j.foodcont.2014.06.021

Foulquié Moreno, M. R., Sarantinopoulos, P., Tsakalidou, E., \& De Vuyst, L. (2006). The role and application of enterococci in food and health. International Journal of Food Microbiology, 106(1), 1-24. https://doi.org/10.1016/j.ijfoodmicro.2005.06.026

Garbeva, P., Van Veen, J. A., \& Van Elsas, J. D. (2004). Microbial diversity in soil: Selection of microbial populations by plant and soil type and implications for disease suppressiveness. Annual Review of Phytopathology, 42, 243-270. https://doi.org/10.1146/annurev.phyto.42.012604.135455

Giard, J. C., Laplace, J. M., Rince, A., Pichereau, V., Benachour, A., Leboeuf, C., Flahaut, S., Auffray, Y., \& Hartke, A. (2001). The stress proteome of Enterococcus faecalis. Electrophoresis, 22(14), 2947-2954.
https://doi.org/10.1002/1522-2683(200108)22:14\%3C2947::AIDELPS2947\%3E3.0.CO;2-K

Giraffa, G. (2002). Enterococci from foods. FEMS Microbiology Reviews, 26(2), 163-171. https://doi.org/10.1111/j.1574-6976.2002.tb00608.x

Gong, H. S., Meng, X. C., \& Wang, H. (2010). Plantaricin MG active against Gram negative bacteria produced by Lactobacillus plantarum KLDS1 isolated from "Jiaoke", a traditional fermented cream from China. Food Control, 21(1), 89-96. https://doi.org/10.1016/j.foodcont.2009.04.005

Hadji-Sfaxi, I., El-Ghaish, S., Ahmadova, A., Batdorj, B., Le Blay-Laliberté, G., Barbier, G., Haertlé, T., \& Chobert, J.M. (2011). Antimicrobial activity and safety of use of Enterococcus faecium PC4.1 isolated from Mongol yogurt. Food Control, 22(12), 2020-2027. https://doi.org/10.1016/j.foodcont.2011.05.023

Hanchi, H., Mottawea, W., Sebei, K., \& Hammami, R. (2018). The Genus Enterococcus: between probiotic potential and safety concerns-an update. Frontiers in Microbiology, 9 ,

1791

https://doi.org/10.3389/fmicb.2018.01791

Hardwood, V. J., Whitlock, J., \& Withighton, V. (2000). Classification of antibiotic resistance patterns of indicator bacteria by discriminant analysis: use in predicting the source of fecal contamination in subtropical waters. Applied and $\begin{array}{llll}\text { Environmental } & \text { Microbiology, } & \text { 66(9), }\end{array}$ https://doi.org/10.1128/aem.66.9.3698-3704.2000

Hassaïne, O., Zadi-Karam, H., \& Karam, N. E. (2007). Technologically important properties of lactic acid bacteria isolated from raw milk of three breeds of Algerian dromedary (Camelus dromedarius). African Journal of Biotechnology, 6(14), 1720-1727. https://doi.org/10.5897/AJB2007.000-2251

Hassaïne, O., Zadi-Karam, H., \& Karam, N. E. (2008). Phenotypic identification and technological properties of lactic acid bacteria isolated from three breeds dromedary raw milks in south Algeria. Emirates Journal of Food Agriculture, 20(1), 46-59. https://doi.org/10.9755/ejfa.v12i1.5180

Hosseini, S. V., Arlindo, S., Bohme, K., Fernandez-No, C., Calo-Mata, P., \& Barros-Velazquez, J. (2009). Molecular and probiotic characterization of bacteriocin-producing Enterococcus faecium strains isolated from nonfermented animal foods. Journal of Applied Microbiology, 107(4), 1392-1403. https://doi.org/10.1111/j.1365-2672.2009.04327.x

Khay, E., Idaomar, M., Castro, L. M. P., Bernárdez, P. F., Senhaji, N. S., \& Abrini, J. (2011). Antimicrobial activities of the bacteriocin-like substances produced by lactic acid bacteria isolated from Moroccan dromedary milk. African $\begin{array}{llll}\text { Journal of } \quad \text { Biotechnology, 10(51), } & 10447-10455\end{array}$ http://dx.doi.org/10.5897/AJB11.1328

Klibi, N., Ben Slimen, N., Fhoula, I., López, M., Ben Slama, K., Daffonchio, D. Boudabous, A., Torres, C., \& Ouzari, H. (2012). Genotypic diversity, antibiotic resistance and bacteriocin production of Enterococci isolated from rhizospheres. $\begin{array}{llll}\text { Microbes and } \quad \text { Environments, } & \text { 27(4), }\end{array}$ https://dx.doi.org/10.1264\%2Fjsme2.ME12041

Magnusson, J., \& Schnurer, J. (2001). Lactobacillus coryniformis subsp. coryniformis strain $\mathrm{Si} 3$ produces a broad-spectrum proteinaceous antifungal compound. Applied and Environmental Microbiology, 67(1), 1-5. https://dx.doi.org/10.1128\%2FAEM.67.1.1-5.2001

Mathur, S., \& Singh, R. (2005). Antibiotic resistance in food lactic acid bacteria - a review. International Journal of Food Microbiology, 105(3), 281-295. https://doi.org/10.1016/j.ijfoodmicro.2005.03.008

Merzouk, Y., Chahrour, W., Zarour, K., Zergui, A., Saidi, N., Henni, J. E., \& Kihal, M. (2013). Physico-chemical and microbiological analysis of Algerian raw camel's milk and identification of predominating thermophilic lactic acid bacteria. Journal of Food Science and Engineering, 3, 55-63.

Moore, D. F., Guzman, J. A., \& McGee, C. (2008). Species distribution and antimicrobial resistance of enterococci isolated from surface and ocean water. Journal of Applied Microbiology, 105(4), 1017-1025. https://doi.org/10.1111/j.1365-2672.2008.03828.x

Morrison, D., Woodford, N., \& Cookson, B. (1997). Enterococci as emerging pathogens of humans. In: Andrew P. W., Mitchell T. J., (eds.), The Biology of Streptococci and Enterococci; Oxford, UK: Blackwell Science, pp. 89S-99S.

NCCLS (The National Committee for Clinical Laboratory Standards). (2004). Performance Standards for Antimicrobial Disk and Dilution Susceptibility Tests for Bacteria Isolated from Animals; Informational Supplement, M31-S1. Vol. 24, No. 17, Wayne, Pennsylvania, USA: NCCLS.

Özden Tuncer, B., Ay, Z., \& Tuncer Y. (2013). Occurrence of enterocin genes, virulence factors, and antibiotic resistance in 3 bacteriocin-producer Enterococcus faecium strains isolated from Turkish tulum cheese. Turkish Journal of Biology, 37, 443-449. https://doi.org/10.3906/biy-1209-26

Rivas, F. P., Castro, M. P., Vallejo, M., Marguet, E. R., \& Campos, C. A. (2012) Antibacterial potential of Enterococcus faecium strains isolated from ewes' milk and cheese. Lwt - Food Science and Technology, 46(2), 428-436. https://doi.org/10.1016/j.lwt.2011.12.005

Schirru, S., Todorov, S. D., Favaro, L., Mangia, N. P., Basaglia, M., Casella, S. Comunian, R., Gombossy de Melo Franco, B. D., \& Deiana, P. (2012). Sardinian goat's milk as source of bacteriocinogenic potential protective cultures. Food Control, 25(1), 309-320. https://doi.org/10.1016/j.foodcont.2011.10.060

Tamura, K., Peterson, D., Peterson, N., Stecher, G., Nei, M., \& Kumar, S. (2011) MEGA5: molecular evolutionary genetics analysis using maximum likelihood 
evolutionary distance, and maximum parsimony methods. Molecular Biology and Evolution, 28(10), 2731-2739. https://dx.doi.org/10.1093\%2Fmolbev\%2Fmsr121

Tendolkar, P. M., Baghdayan, A. S, \& Shankar, N. (2003). Pathogenic enterococci: new developments in the 21st century. Cellular and Molecular Life Sciences, 60(12), 2622-2636. https://doi.org/10.1007/s00018-003-3138-0

Vandera, E., Parapouli, M., Kakouri, A., Koukkou, A., Hatziloukas, E., \& Samelis, J. (2020). Structural enterocin gene profiles and mode of antilisterial activity in synthetic liquid media and skim milk of autochthonous Enterococcus spp. isolates from artisan Greek Graviera and Galotyri cheeses. Food microbiology, 86, 103335 . https://doi.org/10.1016/j.fm.2019.103335

Yerlikaya, O., \& Akbulut, N. (2020). In vitro characterisation of probiotic properties of Enterococcus faecium and Enterococcus durans strains isolated from raw milk and traditional dairy products. International Journal of Dairy Technology, 73(1), 98-107. https://doi.org/10.1111/1471-0307.12645

Yoon, M. Y., Kim, Y. J., \& Hwang, H. J. (2008). Properties and safety aspects of Enterococcus faecium strains isolated from Chungkukjang, a fermented soy product. LWT - Food Science and Technology, 41(5), 925-933. https://doi.org/10.1016/j.lwt.2007.05.024

Zamudio-Maya, M., Narvaez-Zapata, J., \& Rojas-Herrera, R. (2008). Isolation and identification of lactic acid bacteria from sediments of a coastal marsh using a differential selective medium. Letters in Applied Microbiology, 46(3), 402-407. https://doi.org/10.1111/j.1472-765X.2008.02329.x 